Reprod. Nutr. Dévelop., 1986, 26 (1 B), 345-346.

\title{
Variations de l'urémie en fonction de la quantité et de la nature des matières azotées alimentaires chez la chèvre en lactation
}

Sylvie GIGER, D. SAUVANT, Michelle DORLĖANS, J. HERVIEU

Station de Nutrition et Alimentation, I.N.R.A., Institut National et Agronomique Paris-Grignon, 16, rue Claude Bernard, 75231 Paris Cédex 05.

Summary. As in other ruminant species, dairy goat plasma urea (PU) is highly correlated with nitrogen intake, dietary crude protein content, urinary nitrogen excretion or digestible nitrogen balance. This study shows that excess degradable nitrogen in the rumen had a significant influence on the PU level and therefore that the PDI system is better than the DCP system in explaining variations in PU. Netherless, PU content was not a fair, accurate predicator of variations in nitrogen balance.

L'urémie est corrélée positivement avec la concentration en ammoniac dans le liquide du rumen, et donc la quantité d'azote ingérée, le taux de matières azotées de la ration et l'apport d'azote fermentescible dans le rumen (Preston et al., 1965 ; Journet et al., 1965).

Le travail présenté a pour objectif de vérifier ces relations établies chez les bovins et les ovins dans le cas de chèvres en lactation et d'évaluer dans quelle mesure, I'urémie est susceptible de traduire des variations du bilan azoté ainsi que des caractéristiques du régime alimentaire exprimées à travers le système PDI (I.N.R.A, 1978).

Matériel et méthodes. Les données correspondent à des valeurs individuelles correspondant à une moyenne sur 5 jours consécutifs de mesures obtenues sur des animaux placés en cage à bilan. L'urémie a été mesurée une fois par semaine sur du plasma issu d'un prélèvement jugulaire effectué le matin avant la distribution du repas. Le foin de luzerne et/ou l'ensilage de maïs qui ont constitué la ration de base ont été associés à différents types d'aliments concentrés, ce qui a permis d'obtenir de larges plages de variations (tabl. 1) de la quantité des matières azotées alimentaires, du taux de satisfaction des besoins azotés et de l'excès d'azote fermentescible par rapport à la matière organique digestible.

TABL. 1. - Principales caractéristiques des paramètres étudiés

\begin{tabular}{lcccc}
\hline & Moyenne & Ecart-type & Minimum & Maxium \\
\hline Teneur en MAT \% MO & 18,4 & 2,3 & 12,0 & 22,4 \\
Teneur en PDI \% MO & 11,1 & 1,3 & 7,2 & 13,4 \\
(PDIN-PDIE) /MOD ou $\triangle \mathrm{PDI}$ & 9,94 & 13,65 & $-14,30$ & 32,67 \\
Quantitiés de N ingéré en g/kg P0,75 & 2,73 & 0,71 & 1,19 & 4,76 \\
Quantités de N urinaire en g/kg P0,75 & 1,22 & 0,45 & 0,48 & 1,95 \\
Quantités de N lait/ en g/kg P0,75 & 0,615 & 0,265 & 0,215 & 1,244 \\
Quantités de N retenu en g/kg P0,75 & 0,114 & 0,283 & $-0,700$ & 0,746 \\
Bilan MAD en g/kg P0,75 (1) & 2,69 & 3,63 & $-7,13$ & 10,38 \\
Bilan PDI en g/kg P0,75 (2) & 1,98 & 2,55 & $-5,31$ & 6,91 \\
Digestibilité azote \% & 71,0 & 5,3 & 53,7 & 79,4 \\
Urémie g/l & 0,628 & 0,218 & 0,160 & 1,100 \\
\hline
\end{tabular}

$n=187$ observations réparties en 29 régimes

(1): $\mathrm{BMAD} / \mathrm{P}^{0,75}=$ (Quantité $\mathrm{N}$ ingéré $\left.\times 6,25-(40,0+0,6(\mathrm{P}-50)+\mathrm{PL} 35 \times 56)\right) / \mathrm{P}^{0,75}$

(2): BPDI $/ \mathrm{P}^{0,75}=$ (Quantité PDI $\left.-(42+0,6(\mathrm{P}-50)+\mathrm{PL} 35 \times 47)\right) / \mathrm{P}^{0,75}$

avec PL35 : Quantité de lait corrigée à 3,5\% de taux butyreux 
Résultats et discussion. L'urémie est liée positivement à la quantité d'azote ingérée et la teneur en matières azotées totales exprimées en \% de la matière organique (MAT \% /MO) de la ration :
Urémie $=0,316+0,114 \mathrm{~N}$ ingéré $(\mathrm{r}=0,38, \mathrm{n}=187, \mathrm{ETR}=0,153)$ $(0,059) \quad(0,021)(\mathrm{g} / \mathrm{kg} \mathrm{P} 0,75)$
Urémie $=-0,665+0,0704 \% \mathrm{MAT} / \mathrm{MO}(\mathrm{r}=0,75, \mathrm{n}=187, \mathrm{ETR}=0,145)$ $(0,085) \quad(0,0046)$

L'urémie n'est pas significativement corrélée avec le bilan azoté mesuré à partir de la quantité d'azote ingérée et des " pertes azotées " sous forme de fèces, d'urine et de lait $(r=0,07)$, mais, par contre, l'est aux bilans calculés avec les systèmes MAD (BMAD) ou PDI (BPDI).

$$
\begin{aligned}
& \mathrm{BMAD} / \mathrm{P}^{0,75}=4,125+10,84 \text { urémie }(r=0,65, \mathrm{n}=187 \text {, ETR }=2,77 \text { ) } \\
& (0,619) \quad(0,93) \\
& \text { BPDI/P0,75 } 2,671+7,40 \text { urémie }(r=0,63, n=187, \text { ETR }=1,98) \\
& (0,444) \quad(0,67)
\end{aligned}
$$

La prise en compte de l'équilibre entre les apports énergétiques et azotés aux microorganismes du rumen $(\Delta \mathrm{PDI}=\mathrm{PDIN}$ - PDIE/MOD $)$ améliore les 3 premières équations :

$$
\begin{aligned}
& \text { Urémie }=0,240+0,104 \mathrm{~N} \text { ingéré }+0,0106 \Delta \mathrm{PDI} \\
& (0,042) \quad(0,015)\left(\mathrm{g} / \mathrm{kg} \mathrm{P}^{0,75}\right) \quad(0,0008) \\
& (\mathrm{r}=0,76, \mathrm{n}=187, \mathrm{ETR}=0,142) \\
& \text { Urémie }=-0,340+0,0502 \% \mathrm{MAT} / \mathrm{MO}+0,00474 \Delta \mathrm{PDI} \\
& (0,110) \quad(0,0064) \quad(0,00108) \\
& (r=0,80, n=187, E T R=0,139) \\
& \mathrm{BMAD} / \mathrm{P}^{0,75}=-2,927+7,81 \text { urémie }+0,0709 \Delta \mathrm{PDI} \\
& (0,686) \quad(1,23) \quad(0,0197) \\
& (r=0,68, n=187, \text { ETR }=2,68)
\end{aligned}
$$

Ces résultats confirment ceux obtenus par Brun-Bellut, et al., (1983) sur les causes de variations des taux d'urée du lait.

D'autre part, la quantité d'azote excrétée par voie urinaire est très liée à l'urémie comme Thornton (1970) l'a montrée chez les bovins :

$\mathrm{N}$ urinaire $=0,298+1,468$ urémie $\quad(r=0,71, \mathrm{n}=187$, ETR $=0,316)$ $\left(\mathrm{g} / \mathrm{kg} \mathrm{P}^{0,75}\right)$.

Ces différentes observations montrent que les caprins réagissent comme les autres ruminants aux variations en quantité des apports azotés. lls soulignent également l'intérêt du système PDI et notamment du critère $\Delta$ PDI pour préciser les variations de l'urémie. Cependant, l'urémie, associée ou non à $\Delta$ PDI, ne semble pas être un prédicteur fiable des bilans azotés.

Brun-Bellut J., Laurent F., Vignon B., 1983. Taux d'urée du lait et utilisation de I'azote par la chèvre laitière. In IV Symp. int. Métabolisme et Nutrition azotées, Ed. INRA Publ., vol. II, no 16, $179-182$.

I.N.R.A., 1978. Azote, 89-128. In Alimentation des ruminants, Ed. I.N.R.A. Publ., route de SaintCyr, 78000 Versailles.

Journet M., Vérité R., Vignon B., 1975. L'azote non protéique du lait : facteurs de variation. Le lait, 55, 212-213.

Preston R.L., Schnakenberg D. D., Pfander W. H., 1965. Protein utilization in ruminants. I. Blood urea nitrogen as affected by protein intake. J. Nutr., 86, 281-288.

Thornton R. F., 1970. Factors affecting the urinary excretion of urea nitrogen in cattle. II. The plasma urea nitrogen concentration. Aust. J. agric. Res., 21, 145-152. 